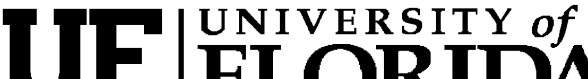 FLORIDA \\ IFAS Extension
}

\section{Bloat In Cattle ${ }^{1}$}

M.B. Irsik, DVM, MAB ${ }^{2}$

\section{Definition and Etiology}

Bloat is the abnormal accumulation of gas in the ruminal forestomachs. Three categories of bloat are (1) frothy bloat caused by diets that lead to the formation of a stable froth or foam in the rumen, (2) free gas bloat caused by diets that lead to excessive gas production and concomitant low intraruminal $\mathrm{pH}$, and (3) free gas bloat caused by failure to eructate from extraruminal causes of gas accumulation such as esophageal obstruction. When bloating occurs, these gases cannot escape, and they continue to build up and cause severe distention of the abdomen, compression of the heart and lungs, and eventually death.

\section{Clinical Signs and Differential Diagnosis}

When cattle experience a case of bloat, the degree of forestomach enlargement and distension can vary. The clinical signs associated with bloat vary from an even filling of the left paralumbar fossa to an extreme abdominal enlargement. Other clinical signs associated with bloat are colic with kicking at the abdomen, treading, frequent lying down and rising, and vocalization. Some animals may exhibit a stretched stance with the rear feet placed far back. As the forestomachs enlarge and the distended rumen compresses the diaphragm, breathing often becomes labored. Open mouth breathing, cyanosis of mucous membranes, and collapse leading to death may occur in extreme cases of bloat.

Other conditions to rule out when evaluating a ruminant for bloat or abdominal pain and distension are peritonitis or an infection within the abdominal cavity, water belly or rupture of the urinary bladder, advanced pregnancy, an accumulation of abnormal amounts of fluid within the uterus during pregnancy, left or right abomasal displacement, vagal indigestion, intestinal volvulus (twisted intestines), ascites (accumulation of fluid within the peritoneal cavity) or pneumoperitoneum (accumulation of air within the peritoneal cavity.

\section{Frothy Bloat}

Frothy bloat is caused by the retention of gas within the mass of ingesta contained within the rumen. This retention of gas within the rumen ingesta leads to the development of froth or foam that the animal is unable to belch because no gas pocket is developed in the dorsal compartment of the rumen.

1. This document is VM164, one of a series of the College of Veterinary Medicine, Department of Large Animal Clinical Sciences, Florida Cooperative Extension Service, Institute of Food and Agricultural Sciences, University of Florida. Original publication date March 14, 2007. Visit the EDIS Web Site at http://edis.ifas.ufl.edu.

2. M.B. Irsik, Beef Cattle Extension Veterinarian, Department of Large Animal Clinical Sciences, College of Veterinary Medicine, Cooperative Extension Service, Institute of Food and Agricultural Sciences, University of Florida, Gainesville, 32610.

The Institute of Food and Agricultural Sciences (IFAS) is an Equal Opportunity Institution authorized to provide research, educational information and other services only to individuals and institutions that function with non-discrimination with respect to race, creed, color, religion, age, disability, sex, sexual orientation, marital status, national origin, political opinions or affiliations. U.S. Department of Agriculture, Cooperative Extension Service, University of Florida, IFAS, Florida A. \& M. University Cooperative Extension Program, and Boards of County Commissioners Cooperating. Larry Arrington, Dean 
Froth bloat is usually associated with diets of lush legumes such as fresh cut forages, winter wheat pasture or concentrated finishing diets.

There are both animal and plant characteristics which may predispose an animal to frothy bloat associated with legumes. Individual cattle have been classified as having high or low susceptibility to legume bloat. Susceptible cattle have larger rumen volumes and characteristics of their saliva which are different from those of bloat-resistant cattle. Plant characteristics which contribute to frothy boat are related to how easily the plant material is macerated and how quickly the inner leaf cells are made available to bacterial activity.

Ionophore antibiotics such as monensin have been shown to aid in the reduction of the bloat potential of some forages.

Frothy bloat associated with concentrate feeding is similar to that caused by legumes. A stable froth is produced within the rumen ingesta with no gas pocket produced within the dorsal compartment of the rumen.

Prevention of frothy boat associated with pastures has historically relied on attempts to identify when the forages were most prone to produce bloat. During these periods, cattle are fed other feeds (hay) or allowed limited access to the problem forages. Predicting periods when forages are prone to produce frothy bloat is not very reliable, so agents which aid in the prevention of frothy bloat have been developed. Feeding Poloxalene or adding surfactants to drinking water have proven to be effective methods for reducing the incidence of frothy bloat. Treating individual animals for frothy bloat would include administering a product containing a surfactant, vegetable oil, or Poloxalene labeled for use in individual animals.

Frothy bloat associated with feeding concentrate rations to cattle is minimized by providing adequate fiber in the ration, feeding an ionophore, and slowly introducing higher proportions of concentrates in rations offered to cattle during their first few weeks on feed. This slow introduction of concentrates allows the rumen microflora to adapt, which helps prevent frothy bloat. When cattle are fed concentrate rations, the incidence of frothy bloat is generally low. However, when there is a high incidence of frothy bloat, the ration being fed, its ingredients, as well as the level of ionophore being fed should be evaluated and adjustments made as needed.

\section{Free Gas Bloat}

Ruminal tympany or free gas bloat usually occurs after an animal consumes an amount of concentrate feed greater than what they are adapted to. Over consumption of feed leads to rapid fermentation within the rumen by the rumen bacteria, over production of volatile organic acids (VFAs), an increase in lactic acid, and lowering of the $\mathrm{pH}$ within the rumen. With the lowered rumen $\mathrm{pH}$, increased production of VFAs and lactic acid, the absorption capacity of the rumen is exceeded, and the contraction of the rumen is inhibited, which allows for an accumulation of gas in the dorsal sac of the rumen.

\section{Incidence Rates for Bloat}

Free gas bloat from causes other than consumption of wet legumes and high concentrate diets occurs sporadically, whereas frothy bloat often occurs as an epidemic. When pasture conditions support rapid early plant growth, there may be an increased incidence of frothy bloat. Cattle grazing cereal grain pastures such as wheat or rye may have an increased incidence of froth bloat in the early spring when the plant is coming out of dormancy or is growing rapidly. Producers are encouraged to be cautious when placing stockers on spring pastures, providing dry roughage or surfactants as needed to help control the incidence of frothy bloat.

\section{Treatment and Prognosis}

For free gas bloat, passage of a stomach tube is generally sufficient to relieve the discomfort of mild to moderate distention of the rumen with free gas. Manipulation and repositioning of the tube after it enters the rumen is sometimes required to deflate the gas pocket. If acidosis is responsible for the incidence of bloat, antacid therapy should be provided in the form of sodium bicarbonate (baking soda $\sim 1 \mathrm{lb}$ in cold water) introduced via the stomach tube. 
If no gas can be released by the introduction of the stomach tube, the cause of the bloat is probably from froth or foam within the rumen. Treatment of this type of bloat should include providing via the stomach tube one of the following: Poloxalene, mineral or vegetable oil, or a surfactant such as dish soap. These products help break down the froth within the rumen into larger pockets of gas which the animal can eructate or which can be relieved via a stomach tube. Care should be taken in treating an animal with frothy or free gas bloat, especially if the animal is in respiratory distress. If the animal is in severe respiratory distress, it may be necessary to provide emergency surgical intervention utilizing a rumen trochar. This emergency intervention will relieve free gas bloat but may be insufficient to relieve frothy bloat. In the case of an animal in respiratory distress with frothy bloat that cannot be relieved, an emergency rumenotomy may be necessary to evacuate the frothy contents. Only in extreme conditions should cattlemen relieve a case of bloat by using a knife to puncture the left paralumbar fossa and rumen. This procedure gives the animal some immediate relief, but it also causes the contents of the rumen to spill into the peritoneal cavity, which creates ideal conditions for a case of secondary peritonitis.

Bloat from extraruminal causes such as esophageal obstruction may be relieved by the passage of a stomach tube. Caution should be exercised when attempting to relieve the obstruction in order to minimize damage to the esophagus.

Bloat either frothy or from free gas accumulation within the rumen will always be a concern for cattle producers. There are steps that can be taken to help decrease the incidence of bloat within a population of cattle as well as ways to treat individual cases of bloat. This document is published as a guide for placeStateFlorida cattle producers when evaluating and treating either individual animals or groups of animals experiencing bloat. 